\title{
Immune dot blot technique for diagnosing infection with Chlamydia trachomatis
}

\author{
C C STOREY, G MEARNS, S J RICHMOND \\ From the North Manchester Regional Virus Laboratory, Booth Hall Children's Hospital, Manchester
}

SUMmARY An immune dot blot test (IDBT) to detect the genus specific lipopolysaccharide chlamydial antigen is described, in which the antigen is trapped on nitrocellulose membrane and then detected with a monoclonal antibody labelled with ${ }^{125}$ iodine. A preliminary comparison of 270 specimens obtained from the endocervix or male urethra showed that the IDBT was more sensitive (sensitivity $90 \%$ ) than a commercial amplified enzyme immunoassay named IDEIA (sensitivity $60 \%$ ) for detecting specimens that yielded Chlamydia trachomatis on culture. Subsequent assessment of 950 urogenital tract specimens in the IDBT and by culture confirmed the sensitivity (92\%) and specificity $(95 \%)$ of the IDBT. At least one of 56 specimens obtained from the eye, however, gave a false positive result, which was probably due to staphylococcal protein $A$ in the specimen. The IDBT provides the basis for a novel simple test for detecting the genus Chlamydia.

Several different immunological techniques that allow detection of Chlamydia trachomatis in clinical material from the eye and genital tract are now available for diagnosing genital chlamydial infection. Tests using fluorescein conjugated monoclonal antibodies, such as MicroTrak (Syva), Chlamyset (Orion), and Imagen (Boots Celltech), can detect the organisms directly in smears obtained from infected mucosal surfaces. Commercial enzyme linked immunosorbent assays (ELISAs) that use either monoclonal (IDEIA, Boots Celltech) or polyclonal ("Chlamydiazyme", Abbott Laboratories) antibodies are also available. These techniques are all quick compared with conventional diagnostic methods that rely on isolating $C$ trachomatis in cell culture, and they avoid the need for viable organisms. Tests can therefore be carried out in laboratories that do not have cell culture facilities. The ELISAs are particularly convenient for laboratories that handle large numbers of specimens, as no microscopy is needed. Although doubts have been expressed about the sensitivity of these newer methods compared with isolation techniques, ${ }^{1-4}$ their convenience and speed has led to their introduction in several clinical laboratories.

Address for reprints: Dr S J Richmond, North Manchester Regional Virus Laboratory, New Holzel Laboratory, Booth Hall Children's Hospital, Charlestown Road, Manchester M9 2AA.

Accepted for publication 18 February 1987
We describe a simple alternative method for immunological detection of $C$ trachomatis, in which the genus specific lipopolysaccharide antigen ${ }^{5}$ is trapped on nitrocellulose membrane and then detected by autoradiography with a radiolabelled genus specific monoclonal antibody. This immune dot blot technique compared well with conventional culture in its sensitivity, and with a currently available commercial ELISA kit, which uses the same monoclonal antibody, in its convenience. As the lipopolysaccharide antigen is found in all members of the Chlamydia genus, this technique may also be useful for diagnosing human respiratory infections caused by recently described atypical Chlamydia psittaci organisms, ${ }^{6}$ as well as in veterinary medicine.

\section{Materials and methods}

CLINICAL MATERIAL

We assessed specimens submitted to the North Manchester Regional Virus Laboratory (NMRVL) for routine diagnosis of $C$ trachomatis infection. Most material consisted of endocervical swabs from women and urethral swabs from men who attended the genitourinary medicine (GUM) clinic at the Manchester Royal Infirmary. Similar specimens were also obtained from GUM clinics at Stockport Royal Infirmary, Oldham District General Hospital, Rochdale Infirmary, Bury General Hospital, and Tameside General Hospital. We tested 1220 such specimens. We 
also examined 56 conjunctival swabs obtained from patients who attended the Manchester Royal Eye Hospital, or from other sources within the catchment area of the NMRVL. All swabs were collected in $1.5-2 \mathrm{ml}$ sucrose phosphate transport medium, which contained antibiotics but no serum. ${ }^{7}$ Most specimens were cultured within 24 hours of collection. The remainder were stored at $-160^{\circ}$ in liquid nitrogen before they were tested.

\section{ISOLATION OF CHLAMYDIAE}

Isolation was attempted in cycloheximide treated McCoy cells by a standard technique. ${ }^{7}$ Inclusions were identified by indirect immunofluorescence with a hyperimmune rabbit serum raised against $C$ trachomatis, serotype L2. Two positive control specimens were included in each batch of specimens cultured. One of these controls consisted of previously identified culture positive specimens that had been pooled and stored in aliquots at $-70^{\circ} \mathrm{C}$; each aliquot produced about $10^{3}$ inclusions per McCoy cell monolayer. In addition, a weak positive control was made from a high titred cell culture stock of $C$ trachomatis, serotype $\mathrm{E}$. This was titrated in McCoy cell monolayers, and an appropriate dilution was stored at $-70^{\circ} \mathrm{C}$ in aliquots adjusted to yield less than 10 inclusions per monolayer.

\section{MONOCLONAL ANTIBODY}

Purified monoclonal antibody, $\mathrm{J} 12$, which reacts with a chlamydia specific epitope on the lipopolysaccharide antigen, ${ }^{8}$ was kindly supplied by Boots Celltech. It was stored at $-70^{\circ} \mathrm{C}$ in aliquots that each contained $10 \mu \mathrm{g}$ protein, and an aliquot was radiolabelled as necessary with ${ }^{125}$ iodine according to the method of Hunter et al..$^{9}$ Labelled antibody was stored at $4^{\circ} \mathrm{C}$ during use.

\section{IMMUNE DOT BLOT TEST (IDBT)}

After $0.4 \mathrm{ml}$ of each specimen had been removed for culture for $C$ trachomatis, specimens were placed either in a boiling water bath or exposed to steam in an autoclave for 15 minutes and then centrifuged at low speed for 10 minutes to pellet cellular debris. A 96 well Biodot microfiltration apparatus (Biorad Laboratories Ltd, Watford, Hertfordshire) was assembled with a nitrocellulose membrane moistened in phosphate buffered saline (PBS) pH 7.2. A $0.4 \mathrm{ml}$ volume of clinical specimen was added to each well ( 1 well per specimen) and these were drawn through the nitrocellulose membrane by suction. After about 15 minutes the residue of any specimen that had not been completely drawn through the nitrocellulose membrane was removed from the well by aspiration. The nitrocellulose membrane was then placed in PBS that contained $5 \% \mathrm{w} / \mathrm{v}$ powdered skimmed milk and either left at $4^{\circ} \mathrm{C}$ overnight or held at $37^{\circ} \mathrm{C}$ for a min- imum of 30 minutes. The nitrocellulose membrane was then washed once in PBS with $0.05 \%$ (v/v) Tween 20 (polysorbate 20) (PBST) and incubated for 2 $\frac{1}{2}$ hours at $35^{\circ} \mathrm{C}$ in $40 \mathrm{ml}$ PBST with $5 \%$ milk, to which monoclonal antibody labelled with ${ }^{125}$ iodine $(2 \times$ $10^{6}$ counts per minute (cpm)) was added. The nitrocellulose membrane was washed very thoroughly in PBST for 30 minutes (six changes of PBST), dried, and autoradiographed with Kodak X-OMATIC S1596 film and Super-rapid screens. The nitrocellulose membrane was exposed to pre-flashed film for 24 hours at $-70^{\circ} \mathrm{C}$ and then re-exposed for 72 hours to film that had not been pre-flashed. After development, the film was examined on a light box, and a specimen was considered to be positive when a solid dot could be seen in a position on the film that corresponded to the position of one of the specimen wells on the nitrocellulose membrane. The Biorad apparatus was washed thoroughly in running tap water for about 30 minutes after each batch of specimens had been tested.

A preliminary three way comparison of the IDBT with culture and a commercial ELISA (see below) was carried out on 270 urogenital specimens (139 from men and 131 from women). The remaining clinical material (487 urethral, 463 endocervical, and 56 ocular specimens) were assessed by IDBT and culture only. The sensitivities, specificities, and predictive values of the two immune assays were calculated, based on the assumption that the culture technique was $100 \%$ sensitive and specific.

In addition, twofold dilutions of a high titred stock of $C$ trachomatis serotype E were made in PBS, boiled for 15 minutes, and tested by IDBT. This stock contained about $10^{7}$ inclusion forming units (ifu) per $\mathrm{ml}$ when freshly prepared material was titrated in cycloheximide treated McCoy cell monolayers.

IDEIA

This commercial ELISA (Boots Celltech Diagnostics Ltd, Slough, Berkshire) detects the genus specific lipopolysaccharide chlamydial antigen and it utilises the same monoclonal antibody that was used in the IDBT (see above). The test was carried out according to the manufacturer's instructions, except that specimens were collected into sucrose phosphate transport medium rather than the medium supplied in the kit. This was so that a single specimen could be assayed in three different tests (culture, IDBT, and IDEIA). The 270 genital specimens assessed in this way were boiled before the two antigen assays were performed. The IDEIA was performed in eight well plastic strips, and one well was used per specimen. Results were assessed by measuring the absorbance of each specimen at $490 \mathrm{~mm}$ in a Uniskan spectrophotometer (Labsystems). 
Results

\section{ID B T}

This test proved simple to perform. It needed fewer manipulations than an ELISA test, as procedures in individual wells were avoided once the specimens had been dotted on the nitrocellulose membrane. The autoradiographs were easy to read and provided a permanent visual record of each test, which could be compared directly with subsequent results. When the $C$ trachomatis serotype E stock was tested by IDBT, solid black dots that decreased in density as the organisms were diluted (fig 1) were produced on the autoradiograph. The IDBT was able to detect a minimum of about $10^{2}$ ifu in this material propagated by cell culture (three separate titrations; results not shown in detail). In these titrations exposure of nitrocellulose membrane for 72 hours proved marginally more sensitive than exposure for 24 hours only, so nitrocellulose membrane dotted with clinical specimens was exposed for both these periods. Figure 2 shows representative results.

\section{COMPARISON OF IDBT WITH CULTURE AND ELISA}

Table 1 summarises the results of the three way comparison of 250 urogenital specimens. Results for endocervical and urethral specimens were combined because there was no difference in the performance of these two types of specimen in either antigen detection test. The IDBT proved to be considerably more sensitive than the ELISA (sensitivities $90 \%$ and $60 \%$ respectively) under our conditions of test, which used sucrose phosphate transport medium rather than the transport medium recommended by the manufacturers. The maximum sensitivity of the IDBT was, however, only achieved on 72 hour autoradiographs.

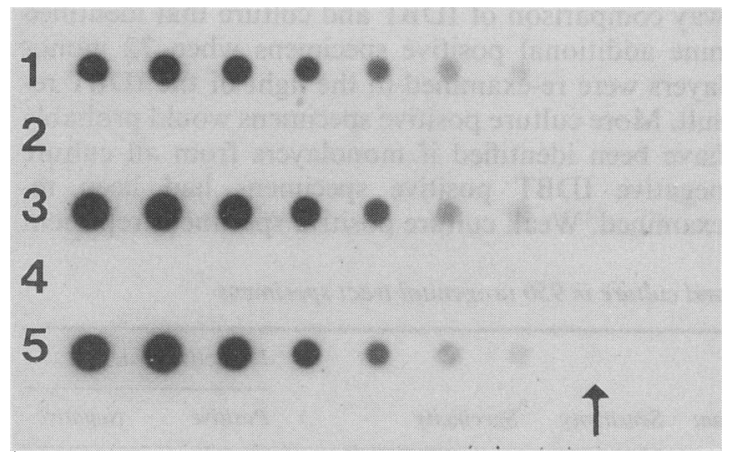

Fig 1 Autoradiograph of twofold titration of Chlamydia trachomatis serotype E tested in triplicate (lanes 1, 3, and 5) in the immune dot blot test (IDBT). Uninfected McCoy cell material titrated in lanes 2 and 4. End point (arrowed) detected $10^{2}$ inclusion forming units.

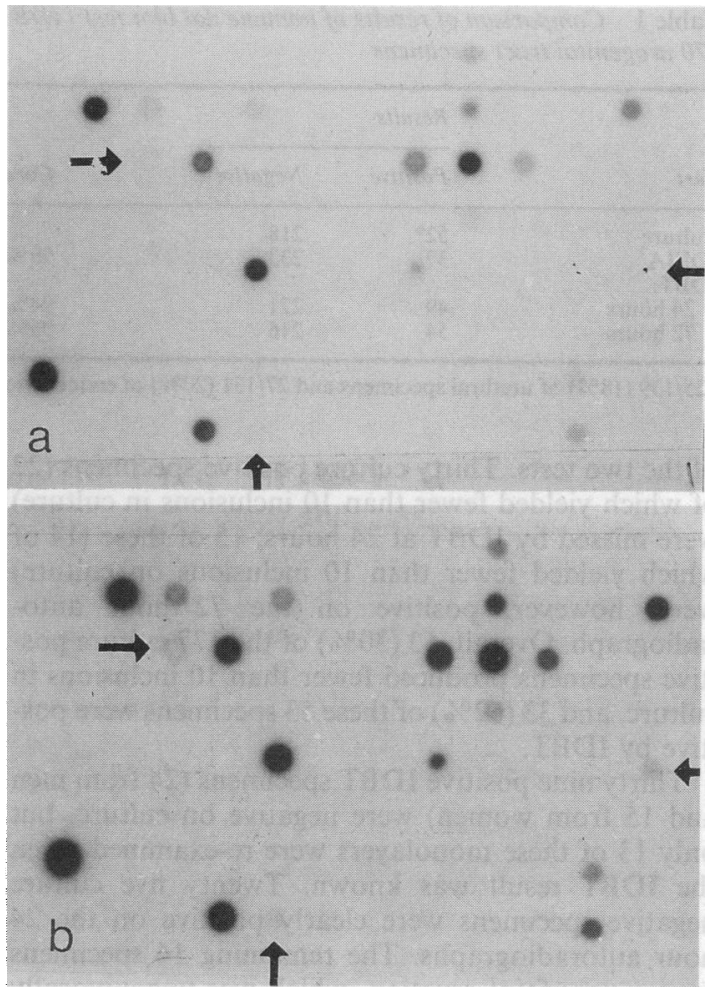

Fig 2 Autoradiographs of 96 clinical specimens tested in the immune dot blot test (IDBT). Nitrocellulose membrane exposed for (a) 24 hours then (b) 72 hours. Three specimens (arrowed) very faintly positive and scored "equivocal" at 24 hours were clearly positive at 72 hours.

Specimens from seven patients were positive by IDBT but negative on culture. Two of these patients proved culture positive when tested again; follow up specimens were not available from the other five patients, who had presented with gonorrhoea (one patient), non-gonococcal urethritis (three patients), or as a female contact of a man with non-gonococcal urethritis. Five culture positive specimens were negative by IDBT; each of these specimens yielded low numbers of inclusions (fewer than 10) on culture.

COMPARISON OF IDBT WITH CULTURE (GENITAL SPECIMENS)

In this comparison, $22 \mathrm{McCoy}$ cell monolayers inoculated with a specimen that was positive by IDBT but initially negative by culture, were carefully reexamined when the IDBT result was known, and nine additional culture positive specimens, which had all produced very few inclusions, were identified. These infections would not have been recognised under our normal culture conditions. Table 2 summarises results 
Table 1 Comparison of results of immune dot blot test (IDBT), commercial enzyme immunoassay (IDEIA), and culture in 270 urogenital tract specimens

\begin{tabular}{|c|c|c|c|c|c|c|c|}
\hline \multirow[b]{2}{*}{ Test } & \multicolumn{2}{|l|}{ Results } & \multirow[b]{2}{*}{ Concordant } & \multirow[b]{2}{*}{ Sensitivity } & \multirow[b]{2}{*}{ Specificity } & \multicolumn{2}{|c|}{ Predictive value } \\
\hline & Positive & Negative & & & & Positive & Negative \\
\hline $\begin{array}{l}\text { Culture } \\
\text { IDEIA }\end{array}$ & $\begin{array}{l}52^{*} \\
37\end{array}$ & $\begin{array}{l}218 \\
233\end{array}$ & $90 \%$ & $60 \%$ & $97 \%$ & $84 \%$ & $91 \%$ \\
\hline $\begin{array}{l}\text { IDBT: } \\
24 \text { hours } \\
72 \text { hours }\end{array}$ & $\begin{array}{l}49 \\
54\end{array}$ & $\begin{array}{l}251 \\
216\end{array}$ & $\begin{array}{l}94 \% \\
96 \%\end{array}$ & $\begin{array}{l}81 \% \\
90 \%\end{array}$ & $\begin{array}{l}97 \% \\
97 \%\end{array}$ & $\begin{array}{l}86 \% \\
87 \%\end{array}$ & $\begin{array}{l}96 \% \\
98 \%\end{array}$ \\
\hline
\end{tabular}

*25/139 (18\%) of urethral specimens and $27 / 131(20 \%)$ of endocervical specimens were culture positive.

of the two tests. Thirty culture positive specimens ( 22 of which yielded fewer than 10 inclusions in culture) were missed by IDBT at 24 hours; 15 of these (14 of which yielded fewer than 10 inclusions on culture) were, however, positive on the 72 hour autoradiograph. Overall, $53(30 \%)$ of the 177 culture positive specimens produced fewer than 10 inclusions in culture, and $33(62 \%)$ of these 53 specimens were positive by IDBT.

Thirty nine positive IDBT specimens ( 24 from men and 15 from women) were negative on culture, but only 13 of these monolayers were re-examined when the IDBT result was known. Twenty five culture negative specimens were clearly positive on the 24 hour autoradiographs. The remaining 14 specimens gave a very faint reaction, which was unequivocally positive by 72 hours.

\section{COMPARISON OF IDBT WITH CULTURE (OCULAR SPECIMENS)}

One of these specimens (from a 22 year old man with keratoconjunctivitis) was positive in both tests, but six specimens that were negative by culture gave positive results at 24 hours by IDBT. One of these specimens came from a one day old neonate with sticky eyes; bacterial cultures yielded a heavy growth of Staphylococcus aureus. This IDBT result was probably a false positive reaction caused by the presence of staphylococcal protein $\mathrm{A}$ in the specimen. The other five ocular swabs (four from babies aged nine days to five weeks and one from a 21 year old woman) were all obtained from patients whose clinical presentation was compatible with chlamydial eye infection, and at least two patients had had topical antibiotic treatment before the swab was taken. Detailed bacteriology results were not available for all these patients, however, and some of these IDBT reactions were possibly due to staphylococcal protein A.

\section{Discussion}

At present, isolation of $C$ trachomatis in cell culture remains the "gold standard" against which new diagnostic tests for chlamydiae must be assessed. ${ }^{2}$ Nevertheless, culture techniques used by most clinical laboratories are unlikely to identify all chlamydial infections. In this laboratory the culture technique is rigorously controlled, weakly positive control material is included in each batch of specimens tested, and a sensitive immunofluorescent staining technique is used to detect inclusions. No blind passage is carried out, however, and the large number of specimens tested (about 1200 a month) makes big demands on the microscopists who have to scan large numbers of McCoy cell monolayers daily. A proportion of cultures that yield very few inclusions are undoubtedly scored negative, which was shown in the large two way comparison of IDBT and culture that identified nine additional positive specimens when 22 monolayers were re-examined in the light of the IDBT result. More culture positive specimens would probably have been identified if monolayers from all culture negative IDBT positive specimens had been reexamined. Weak culture positive specimens represent

Table 2 Comparison of results of immune dot blot test (IDBT) and culture in 950 urogenital tract specimens

\begin{tabular}{|c|c|c|c|c|c|c|c|}
\hline \multirow[b]{2}{*}{ Test } & \multicolumn{2}{|l|}{ Results } & \multirow[b]{2}{*}{ Concordant } & \multirow[b]{2}{*}{ Sensitivity } & \multirow[b]{2}{*}{ Specificity } & \multicolumn{2}{|c|}{ Predictive value } \\
\hline & Positive & Negative & & & & Positive & Negative \\
\hline $\begin{array}{l}\text { Culture } \\
\text { IDBT: }\end{array}$ & $177^{*}$ & 773 & & & & & \\
\hline $\begin{array}{l}24 \text { hours } \\
72 \text { hours }\end{array}$ & $\begin{array}{l}170 \\
201\end{array}$ & $\begin{array}{l}780 \\
749\end{array}$ & $\begin{array}{l}94 \% \\
94 \%\end{array}$ & $\begin{array}{l}83 \% \\
92 \%\end{array}$ & $\begin{array}{l}97 \% \\
95 \%\end{array}$ & $\begin{array}{l}87 \% \\
81 \%\end{array}$ & $\begin{array}{l}97 \% \\
98 \%\end{array}$ \\
\hline
\end{tabular}

\footnotetext{
*Nine specimens were only identified as culture positive when the monolayer was re-examined.
} 
a considerable proportion of all positive specimens. In our experience, about $30 \%$ of all culture positive specimens identified yield fewer than 10 inclusions. The performance of any alternative chlamydial diagnostic test must therefore be critically assessed against these weak culture positive specimens in particular. An optimally sensitive test would be expected to identify all culture positive specimens and also some positive specimens that were missed in culture. Such an ideal test should also be quick, easy to perform, and economical.

The IDBT described in this report fulfils some, but not all, of these criteria. In the preliminary three way comparison, it performed better than the commercial ELISA, which uses the same monoclonal antibody as the IDBT, but missed five weak culture-positive specimens. The sensitivity of the ELISA in our hands was lower $(60 \%)$ than that reported by a number of other laboratories, ${ }^{10}$ though it agreed with that in one previous study. ${ }^{4}$ Our low sensitivity may have been because the recommended transport medium was not used in our comparison. In the large two way comparison of IDBT and culture, testing 950 urogenital specimens, an additional 39 specimens that were negative by culture were found to be positive by IDBT. These 39 positive IDBT reactions probably reflected true chlamydial infection. The IDBT performance for genital specimens was therefore at least as good as our routine culture technique.

The test is simple and economical to perform and results are easy to read. The use of a radioactive label and the fact that a 72 hour autoradiograph is needed to achieve maximum sensitivity, however, will limit widescale use of the test as it stands. Introduction of a sensitive non-radioactive detection system, which would also give more rapid results, should now be possible.

The work shows that the chlamydial lipopolysaccharide is bound very efficiently to nitrocellulose membrane without the need of a "capture" antibody. Diagnosis of $C$ psittaci infection should therefore also be possible in this IDBT. A recent preliminary report suggests that species specific protein antigens of $C$ trachomatis can also be detected in clinical material on nitrocellulose membrane. ${ }^{11}$ The IDBT may prove useful for the rapid detection of other microbial antigens, and hence provide an alternative to conventional diagnostic ELISAs that "capture" antigens immunologically on plastic or polystyrene surfaces at present.

The presence of staphylococcal protein A is a possible cause of false positive results in many tests that rely on immunological detection of chlamydial antigens, ${ }^{12}$ and it was undoubtedly the cause of at least one false positive result in the 56 ocular specimens that were tested in this study. Attempts are now being made to eliminate this reaction in the IDBT by block- ing the nitrocellulose membrane with serum before it is treated with the monoclonal antibody. Until this is achieved, positive IDBT results on ocular specimens should be interpreted with caution.

In summary, the IDBT has proved a convenient, sensitive, in house test for detecting $C$ trachomatis in specimens from the lower genital tract. It may form the basis of a simple novel test for detecting the chlamydial genus lipopolysaccharide antigen, which could make an important contribution to chlamydial diagnosis in the future.

We thank Boots Celltech for the gift of the monoclonal antibody, Dr DW Gump, who helped in the early stages of the development of the IDBT, and all the clinicians who provided the specimens from their patients. This work was supported by a grant from the North West Regional Health Authority.

\section{References}

1 Lipkin ES, Moncada JV, Shafer M-A, Wilson TE, Schachter J. Comparison of monoclonal antibody staining and culture in diagnosing cervical chlamydial infection. J Clin Microbiol 1986;23:114-7.

2 Ridgway GL. The laboratory diagnosis of chlamydial infection. In: Oriel D, Ridgway G, Schachter J, Taylor-Robinson D, Ward M, eds. Chlamydial infections. Cambridge: Cambridge University Press, 1986:539-49.

3 Schachter J. Rapid diagnosis of sexually transmitted diseasesspeed has a price. Diagn Microbiol Infect Dis 1986;4:185-9.

4 Tjiam KH, Van Heijst BYM, Van Zuuren A, et al. Evaluation of an enzyme immunoassay for the diagnosis of chlamydial infections in urogenital specimens. J Clin Microbiol 1986;23:752-4.

5 Ward ME. Chlamydial classification, development and structure. Br Med Bull 1983;39:109-15.

6 Grayston JT, Kuo C-C, Wang S-P, Altman J. A new Chlamydia psittaci strain, TWAR, isolated in acute respiratory tract infections. N Engl J Med 1986;315:161-8.

7 Richmond SJ, Bailey JMG, Bailey AS, Mearns G. Primary isolation of Chlamydia trachomatis and Chlamydia psittaci in in vitro cell culture. In: Collins $\mathrm{CH}$, Grange JM, eds. Isolation and identification of micro-organisms of medical and veterinary importance. London: Academic Press, 1985; Society for Applied Microbiology Technical Series No 21:297-312.

8 Thornley MJ, Zamze SE, Byrne MD, Lusher M, Evans RT. Properties of monoclonal antibodies to the genus-specific antigen of Chlamydia and their use for detection by reverse passive haemagglutination. J Gen Microbiol 1985;131:7-15.

9 Hunter WM, Greenwood FC, Glover JS. The preparation of ${ }^{131}$ I-labelled human growth hormone of high specific activity. Biochem J 1963;89:114-23.

10 Sherwood D. Evaluation of an immunofluorescence test and an amplified enzyme immunoassay for the direct detection of Chlamydial trachomatis in urino-genital specimens. In: Oriel D, Ridgway G, Schachter J, Taylor-Robinson D, Ward M, eds. Chlamydial infections. Cambridge: Cambridge University Press, 1986:554-7.

11 Patel JD, Joseph JM, Falkler JR. Direct detection of Chlamydial trachomatis in clinical specimens by the dot-immunobinding technique using monoclonal antibody. Abstracts of the 86th annual meeting of the American Society for Microbiology. Washington DC: American Society for Microbiology, 1986:331.

12 Krech T, Gerhard-Fsadni D, Hofmann N, Miller SM. Interference of Staphylococcus aureus in detection of Chlamydial trachomatis by monoclonal antibodies. Lancet 1985;i:1161-2. 